\title{
Comentários sobre o Artigo \\ Robust Estimation for ARCH Models
}

\section{Hélio S. Migon}

Inicialmente desejo parabenizar os autores pelo excelente artigo onde são apresentados desenvolvimentos metodológicos originais e aplicações a dados reais. Seu conteúdo envolve, portanto, mais do que uma mera adaptação de metodologias comuns à área.

Após resumirem os principais aspectos empíricos dos dados financeiros - não normalidade, curtose excessiva, assimetria, etc - os autores apresentam a série de retornos diários dos Brazilian Brady bond-C-bond, destacando que esta exibe alguns pontos extremos: crise mexicana 94 e outros dois no final de 1997. Motivam, desta forma, a questão central do artigo: Como esses pontos extremos influenciam os estimadores de máxima verossimilhança? Para evitar esta influência propõem um procedimento de estimação resistente a outliers, o qual é definido a partir da minimização de uma função limitada dos resíduos quadráticos, padronizados por uma medida de escala robusta.

Alguns pontos merecem ser comentados. Primeiramente, a justificativa dos autores para o uso de outliers aditivos é questionável. Não é difícil imaginar argumentos econômicos que suportassem outros modelos de contaminação. Por exemplo, novidades que surgem no m ercado poderiam perder efeito gradualmente, o que dificilmente seria captado pelo modelo proposto.

De outro lado, as propriedades teóricas apresentadas são válidas para a classe dos modelos ARCH. Como os modelos utilizados nas aplicações são GARCH, fica a dúvida se estas continuam válidas.

\begin{tabular}{llll}
\hline R. de Econometria & Rio de Janeiro & v. 19, $\mathrm{n}^{\mathrm{Q}}$ 1, pp. 197-198 & Maio 1999 \\
\hline
\end{tabular} 
Analogamente, será que a distribuição da estatística de Ljung-Box fica inalterada diante do método proposto? Ou de outra forma, as comparações realizadas são realmente válidas?

Finalizando, a questão mais relevante diz respeito a forma como a influência dos resíduos é tratada. Relembrando, a função de verossimilhança (equação 6 do texto), é dada por:

$$
-\frac{1}{n}\left[\sum_{t} \rho\left(\frac{e_{t}^{2}}{\sigma_{t}^{2}}\right)+\sum_{t} \log \left(\sigma_{t}^{2}\right)\right]
$$

onde $e_{t}$ são os resíduos, $\sigma_{t}^{2}$ a variância condicional e $\rho($ ) uma função suave cujo propósito é limitar o efeito dos resíduos. Me questiono se a contribuição da parcela $\log \left(\sigma_{t}^{2}\right)$ não é também relevante, pois depende dos resíduos defasados. 